\title{
Muscle relaxants: \\ a clinical update
}

François Donati PhD MD FRCPC

$\mathrm{T}$

HE introduction of muscle relaxants into clinical anesthesia 60 years ago has revolutionized our specialty, for reasons that were not entirely obvious at the time. Although the need for drugs that provide unconsciousness and analgesia seems obvious, there is no intuitive reason why an agent causing paralysis of skeletal muscle would be such a great advance. The subsequent popularity of the drugs known as muscle relaxants, more accurately called neuromuscular blocking agents, indicates that anesthesiologists were impressed by their advantages in the clinical setting. Thanks to neuromuscular blocking agents, the dosage of concomitant drugs, and their cardiovascular effects, could be limited, immobility could be guaranteed during difficult surgical procedures, mechanical ventilation could be performed more efficiently, and sicker patients could get the benefit of surgery.

During most of these years, there has been a search for better and safer neuromuscular blocking agents, with predictable onset and duration, devoid of cardiovascular effects. As new drugs get better, it is harder to replace them, and the last neuromuscular blocking agent to be introduced, rapacuronium, was withdrawn two years ago because of unforeseen problems. There may be another non-depolarizing drug that might be developed within the foreseeable future, but another approach might be to improve reversal.

With the availability of new narcotic drugs, such as remifentanil, and short acting iv and inhalational agents, the need for neuromuscular blocking agents has been questioned, because the cardiovascular effects of hypnotic and analgesic drugs can be limited by easy titration. In spite of the greater flexibility of these new agents, neuromuscular blocking agents have been shown recently to improve intubating and surgical conditions.

The upper airway has been found to be particularly sensitive to the effects of neuromuscular blocking agents. This concept requires a new understanding of the impact of the different sensitivities of different muscles on clinical parameters, such as onset, maximum blockade and duration, and the best monitoring method. Finally, one needs to reassess the safety of the widespread tendency to omit reversal, again because of the sensitivity of the airway muscles.

\section{New drugs}

In 2000, rapacuronium, a new non-depolarizing neuromuscular blocking agent, was released in the United States. It was a low-potency, rapid onset, short duration drug that had the possibility to replace succinylcholine, at least partly. Doses of $1.5 \mathrm{mg} \cdot \mathrm{kg}^{-1}$ produced relaxation in $1-1.5 \mathrm{~min}$, and the drug could be reversed in $15 \mathrm{~min}$. One year later, rapacuronium was withdrawn because many cases of severe bronchospasm on intubation had been reported. ${ }^{1}$ The mechanism of this action is uncertain, but might be related to the preferential effect of rapacuronium on pre-synaptic muscarinic (M2) receptors in the lung, over postsynaptic (M3) receptors. ${ }^{2}$ It is not a histamine-related or an allergic phenomenon. The only other compound that has been tested in humans and may undergo further clinical development is GW280430A. It has a fast onset (1-1.5 min) and short duration of action $(12 \mathrm{~min}) .^{3}$

Recently, a new concept has emerged. Instead of depending on neuromuscular blocking agents with fast onset and short duration, attempts have been made to find a more efficient way to achieve reversal. Anticholinesterase drugs have a ceiling effect. It is impossible to obtain more than $100 \%$ enzyme inhibition, and the maximum amount of acetylcholine that can be released imposes a limit to the effectiveness of anticholinesterase agents. The new approach consists of binding neuromuscular blocking agents and reducing their concentration in plasma to near zero. This is accomplished by a new type of drug, belonging to a class of compounds called cyclodextrins. The new antagonist (Org 25969) consists of a ring of eight sugars. Rocuronium binds to the centre of this molecule, and the kidney excretes this complex. Animal experi-

\footnotetext{
From the Department of Anesthesiology, University of Montreal, Montreal, Quebec, Canada.

Address correspondence to: Dr. François Donati, Department of Anesthesiology, University of Montreal, Maisonneuve-Rosemont Hospital, 5415, l'Assomption blvd, Montreal, Quebec HIT 2M4, Canada. Phone: 514-252-3426; Fax: 514-252-3542;

E-mail: francois.donati@umontreal.ca
} 
ments have shown that very deep blocks can be antagonized that way, and early human trials have not shown any serious adverse effect of the drug. ${ }^{4}$ This cyclodextrin and the new neuromuscular blocking agent are still a few years before their clinical introduction.

\section{Yes, we need muscle relaxants}

Neuromuscular blocking agents are not needed for all surgical procedures. However, there is still controversy about when they are required and how much is needed. The answer depends on how much hypnotic and narcotic is on board, but also on the skill of the surgeon. There have been few controlled studies on the topic, but three deserve comment. The first of these studies dealt with recovery times when the amount of sevoflurane given was adjusted according to the bispectral index (BIS) value. ${ }^{5}$ Patients had a faster emergence from anesthesia if the BIS value was 60 instead of not measured at all, but more mivacurium was needed, indicating that more neuromuscular blocking agents are required if anesthesia is light. In another study on Cesarean section under general anesthesia, surgeons were allowed to activate a foot pedal to give more mivacurium whenever they thought relaxation was inadequate. In the control group, the anesthesiologist injected mivacurium according to the response of the nerve stimulator. Surgeons actually gave less neuromuscular blocking agent than anesthesiologists,${ }^{6}$ indicating that it is not always necessary to provide complete neuromuscular blockade. Finally, in a more recent study, King et al. ${ }^{7}$ gave either vecuronium or placebo to patients undergoing radical prostatectomy under isoflurane anesthesia. In the placebo group, the surgical conditions were judged to be poor in only $28 \%$ of cases. However, conditions were clearly better in the group receiving vecuronium, where such inadequate conditions were seen in only $2 \%$ of patients. Taken together, these studies suggest that the dose of neuromuscular agent required for a given procedure varies greatly. It may be necessary in some instances to keep blockade complete at the adductor pollicis (no twitch in response to stimulation of the ulnar nerve). For other procedures, it is not necessary to give neuromuscular agents when twitch height returns. Other criteria, such as surgical conditions and ease of ventilation, should also be used.

There are more data available for tracheal intubation. With the recent availability of narcotics with a rapid onset of action, such as alfentanil and remifentanil, it has become possible to consider the possibility of intubating the trachea under reasonable conditions without neuromuscular blocking agents. Almost every combination of hypnotic (usually propo- fol), narcotic, with or without adjuvant drugs such as lidocaine and glycopyrrolate has been tried. When a control group with neuromuscular blocking agent was included, succinylcholine was used in most studies, with modest doses of hypnotic and narcotic. No study reported intubating conditions worse with neuromuscular blocking agent compared with any dose of hypnotic and narcotic. When no neuromuscular blocking agent was used, heavy doses of narcotic and hypnotic were required to obtain adequate intubating conditions, and invariably, this was the dose range where cardiovascular effects were seen. ${ }^{8}$ Typical doses are alfentanil, $60 \mu \mathrm{g} \cdot \mathrm{kg}^{-1}{ }^{9}$ and remifentanil $4-5 \mu \mathrm{g} \cdot \mathrm{kg}^{-1} 10$ with propofol $2-3 \mathrm{mg} \cdot \mathrm{kg}^{-1}$. In this dose range, the duration of remifentanil-induced apnea is longer than that produced by succinylcholine. ${ }^{11}$

Moreover, there is evidence that even modest doses of neuromuscular blocking agents can be associated with good intubating conditions, when given with moderate doses of hypnotic and narcotic. For example, a remifentanil-propofol induction will yield 7\% excellent intubating conditions if no rocuronium is used. If 0.3 $\mathrm{mg} \cdot \mathrm{kg}^{-1}$ rocuronium is used, the rate of excellent conditions increases to $43 \%$ and with 0.6 to $87 \% .^{12}$ Thus, for tracheal intubation, a balanced approach is best: hypnosis, analgesia, and muscle relaxation. The cost of removing one of these elements is high.

\section{Different muscles}

The sensitivity to neuromuscular blocking agents of all the muscles of the body is not the same. Blood flow is not the same either, and this is important because drugs are carried to their site of action via the blood stream. This means that differences in onset, maximum block and duration of action between different muscles may be the result of different blood flows and/or sensitivity. In addition, the dose has to be taken into consideration. Fortunately, it is possible to simplify a bit. Onset time is affected chiefly by blood flow. Perfusion of muscle is greater in the centrally located muscles (diaphragm, other respiratory muscles, larynx, upper airway, eye muscles) than peripheral muscles (hand and feet). Thus, onset is normally faster in centrally located muscles. Maximum block is largely determined by sensitivity, that is how much is required to have an effect. For example, most upper airway muscles (tongue, masseter, pharynx,...), those that keep the airway patent, are known to be sensitive to neuromuscular blocking agents, that is, only small doses are needed to produce an effect. ${ }^{13}$ On the opposite, the diaphragm and the laryngeal adductors are much more resistant, that is, a much larger dose is required to block these muscles. Maximum block and 
recovery time depend largely on sensitivity. For a given dose, block will be greater and duration of action longer in sensitive than in resistant muscles. If large doses are given, 100\% block is obtained in all muscles, but the diaphragm recovers before the upper airway. If a smaller dose is given, it may never block the diaphragm entirely, but it may produce $100 \%$ in the upper airway muscles. Abdominal muscles have an intermediate sensitivity. ${ }^{14}$

The adductor pollicis is a relatively sensitive muscle. Thus it mirrors blockade in the upper airway muscles quite well and is useful for recovery. Sometimes, the facial nerve is stimulated near the eye for monitoring purposes. Contrary to what has been thought in the past, the muscle that moves the eyebrow is not the orbicularis oculi, but the corrugator supercilii. ${ }^{15}$ This muscle has approximately the same sensitivity as the diaphragm and the laryngeal adductors, so it is a good monitor of deep blockade. It is best used to predict intubating conditions, but should not be used as a guide for reversal. For clinical purposes, it may be useful to think of physiologically important muscles as belonging to three groups (Table). First, the resistant muscles with fast onset, which include the diaphragm, the laryngeal adductors, and the corrugator supercilii, require large doses of neuromuscular blocking agent and recover early. The muscles of the upper airway are fast-onset muscles with a high sensitivity to neuromuscular blocking agents and recover late. Finally, peripheral muscles are generally sensitive, but onset is slow. Recovery is also late.

\section{Reversal: always necessary?}

The duration of action of neuromuscular blocking agents available now is shorter than what was available in the past. Mivacurium has a short recovery time. Rocuronium has a short duration of action, especially if small doses are used. Is reversal always necessary? The threshold for adequate respiratory function was considered in the past to be a train-of-four ratio of 0.7 (fourth twitch height divided by first twitch height). The data to support this guideline originated from a study involving six volunteers given d-tubocurarine. ${ }^{16}$ More sophisticated data have been produced since, and the threshold for adequate recovery is now thought to be closer to 0.9. The main lines of evidence come from studies performed in volunteers where a decrease in the ability to swallow was impaired when the train-of-four ratio was 0.9 or less. ${ }^{17}$ Also, the ability to hold a tongue depressor between one's teeth (a measure of the strength of the upper airway muscles) does not return unless a mean train-of-four ratio is 0.86 , and this value might be greater in some patients. ${ }^{18}$
TABLE Time course of muscle relaxation in three groups of muscle

\begin{tabular}{llll}
\hline Muscles & Onset & Maximum block & Recovery \\
\hline $\begin{array}{l}\text { Diaphragm } \\
\begin{array}{l}\text { Laryngeal adductors } \\
\text { Corrugator supercilii }\end{array}\end{array}$ & Fast & Shallow & Early \\
$\begin{array}{l}\text { Upper airway } \\
\text { Orbicularis oculi }\end{array}$ & Fast & Deep & Late \\
$\begin{array}{l}\text { Adductor pollicis } \\
\begin{array}{l}\text { Other hand muscles } \\
\text { Foot muscles }\end{array}\end{array}$ & Slow & Deep & Late \\
\hline
\end{tabular}

The problem is that even with neuromuscular monitoring, it is difficult to estimate fade. Unless one uses a monitor that measures train-of-four response exactly, it is impossible to assess fade with one's senses when actual train-of-four ratio is in the range 0.4 or greater. ${ }^{19}$ Thus, significant residual paralysis may be missed. It is also difficult to rely on the drug's duration of action to rule out any residual paralysis. For example, train-of-four ratios of 0.7 or less (let alone 0.9 ) have been found even four hours after injection of an intubating dose of vecuronium. ${ }^{20}$ In a study where intermediate duration agents but no reversal was given, $42 \%$ of patients had a train-of-four ratio of 0.7 or less in the recovery room..$^{21}$ Residual paralysis has been associated with a higher incidence of oxygen desaturation, hypercapnia, ${ }^{22}$ and postoperative atelectasis. ${ }^{23}$ Thus, the decision to omit reversal should be reserved to cases where the adequacy of recovery has been verified by objective means (a monitor showing the actual train-of-four ratio) or when recovery from the last dose of short- to intermediate-acting agent has been documented to start several hours before.

\section{Conclusion}

The doses of neuromuscular blocking agents must be chosen in such a way as to allow enough spontaneous recovery to occur before the end of the procedure so that anticholinesterase-assisted recovery is possible. Stimulation of the facial nerve and assessment of the response of the corrugator supercilii is useful to predict intubating conditions and as a guide to deep blockade. However, the adequacy of recovery is best assessed by adductor pollicis monitoring.

\section{References \\ 1 Schulman SR. Rapacuronium redux. Anesth Analg 2002; 94: 483-4.}


2 Stuth EA, Stucke AG, Setlock MA. Another possible mechanism for bronchospasm after rapacuronium. Anesthesiology 2002; 96: 1528-9.

3 Savarese JJ, Belmont MR, Lien CA, Boros E, Patel S. Comparative neuromuscular blocking properties of GW 280430 and rocuronium in the thumb and larynx of human subjects. Can J Anesth 1999; 46: A37.

4 Gijsenbergh F, Ramael S, De Bruyn S, Rietbergen H, van Iersel T. Preliminary assessment of Org 25969 as a reversal agent for rocuronium in healthy male volunteers. ASA Abstracts 2002: A1018.

5 Song D, van Vlymen J, White PF. Is the bispectral index useful in predicting fast-track eligibility after ambulatory anesthesia with propofol and desflurane? Anesth Analg 1998; 87: 1245-8.

6 Abdulatif M, Taylouni E. Surgeon-controlled mivacurium administration during elective caesarean section. Can J Anaesth 1995; 42: 96-102.

7 King M, Sujirattanawimol N, Danielson DR, Hall BA, Schroeder DR, Warner DO. Requirements for muscle relaxants during radical retropubic prostatectomy. Anesthesiology 2000; 93: 1392-7.

8 Donati F. Tracheal intubation: unconsciousness, analgesia and muscle relaxation (Editorial). Can J Anesth 2003; 50: 99-103.

9 Scheller MS, Zornow MH, Saidman LJ. Tracheal intubation without the use of muscle relaxants: a technique using propofol and varying doses of alfentanil. Anesth Analg 1992; 75: 788-93.

10 Alexander R, Olufolabi AJ, Booth J, El-Moalem HE, Glass PS. Dosing study of remifentanil and propofol for tracheal intubation without the use of muscle relaxants. Anaesthesia 1999; 54: 1037-40.

11 McNeil IA, Culbert B, Russell I. Comparison of intubating conditions following propofol and succinylcholine with propofol and remifentanil 2 micrograms $\mathrm{kg}^{-1}$ or 4 micrograms kg-1 ${ }^{-1}$ Br J Anaesth 2000; 85: 623-5.

12 Schlaich N, Mertzlufft F, Soltesz S, Fuchs-Buder T. Remifentanil and propofol without muscle relaxants or with different doses of rocuronium for tracheal intubation in outpatient anaesthesia. Acta Anaesthesiol Scand 2000; 44: 720-6.

13 d'Honneur G, Guignard B, Slavov V, Ruggier R, Duvaldestin $P$. Comparison of the neuromuscular blocking effect of atracurium and vecuronium on the adductor pollicis and the geniohyoid muscle in humans. Anesthesiology 1995; 82: 649-54.

14 Kirov K, Motamed C, Dhonneur G. Differential sensitivity of abdominal muscles and the diaphragm to mivacurium. Anesthesiology 2001; 95: 1323-8.

15 Pland B, Debaene B, Donati F. The corrugator supercilii, not the orbicularis oculi, reflects rocuronium neu- romuscular blockade at the laryngeal adductor muscles. Anesthesiology 2001; 95: 96-101.

16 Ali HH, Wilson RS, Savarese JJ, Kitz RJ. The effect of tubocurarine on indirectly elicited train-of-four muscle response and respiratory measurements in humans. Br J Anaesth 1975; 47: 570-4.

17 Eriksson LI, Sundman E, Olsson R, et al. Functional assessment of the pharynx at rest and during swallowing in partially paralyzed humans: simultaneous videomanometry and mechanomyography of awake human volunteers. Anesthesiology 1997; 87: 1035-43.

18 Kopman AF, Yee PS, Neuman GG. Relationship of the train-of-four fae ratio to clinical signs and symptoms of residual paralysis in awake volunteers. Anesthesiology 1997; 86: 765-71.

19 Drenck NE, Ueda N, Olsen NV, et al. Manual evaluation of residual curarization using double burst stimulation: a comparison with train-of-four. Anesthesiology 1989; 70: 578-81.

20 Caldwell JE. Reversal of residual neuromuscular block with neostigmine at one to four hours after a single intubating dose of vecuronium. Anesth Analg 1995; 80: 1168-74.

21 Baillard C, Gehan G, Reboul-Marty J, Larmignat P, Samama CM, Cupa M. Residual curarization in the recovery room after vecuronium. Br J Anaesth 2000; 84: 394-5.

22 Bissinger U, Schimek F, Lenz G. Postoperative residual paralysis and respiratory status: a comparativie study of pancuronium and vecuronium. Physiol Res 2000; 49: 455-62.

23 Berg H, Roed J, Viby-Mogensen J, et al. Residual neuromuscular block is a risk factor for postoperative pulmonary complications. A prospective, randomised, and blinded study of postoperative pulmonary complications after atracuriu, vecuronium and pancuronium. Acta Anaesthesiol Scand 1997; 41: 1095-103. 